\title{
METODOLOGIAS DIFERENCIADAS NO ENSINO DE PSICOLOGIA DA EDUCAÇÃO PARA ALUNOS DO CURSO DE LIBRAS DA UFPI
}

Anne Caroline Soares Dourado ${ }^{1}$ Antonia Dalva França-Carvalho ${ }^{2}$

\section{CONSIDERAÇÕES INICIAIS}

A Língua Brasileira de Sinais (LIBRAS) passou a ser reconhecida como meio legal de comunicação e expressão no Brasil no ano de 2002, quando sancionada a Lei n. 10 436, de 24 de abril de 2002. A Universidade Federal do Piauí (UFPI), no ano de 2014 realizou o primeiro vestibular para o Curso de Licenciatura em Letras/LIBRAS, um desafio para professores, sobretudo aqueles que até então não possuíam domínio sobre a língua de sinais. A Lei não garante que os professores estejam realmente preparados para receber esses alunos e nem que a formação dos mesmos tenha sido suficiente para desenvolver um trabalho digno e satisfatório, que de fato não comprometa a educação de pessoas com deficiência auditiva. $O$ presente trabalho ${ }^{3}$ consiste no recorte do diário de campo, que conta a experiência da disciplina Psicologia da Educação na recém criada turma de Letras/LIBRAS da UFPI, na qual lecionamos em Tirocínio no primeiro semestre de 2015.

A turma era mista, formada por surdos e ouvintes, o que nos conduz a perspectiva de um ensino inclusivo que considere as peculiaridades de todos os alunos. A educação inclusiva é considerada um avanço em relação aos demais movimentos educacionais direcionados a alunos com deficiência auditiva, pois de acordo com Glant e Nogueira (2002) há uma mudança do foco, em que o ensino que se adapta ás necessidades do aluno. Essa educação tornou-se uma proposta de intervenção amparada e fomentada pela legislação, pois a inclusão de alunos com

\footnotetext{
${ }^{1}$ Mestre em Educação. Professora do Curso de Pedagogia, do Campus Amílcar Ferreira Sobral, da Universidade Federal do Piauí. Email: acsdourado@ufpi.edu.br

${ }^{2}$ Doutora em Educação. Professora do Programa em Pós-Graduação em Educação da UFPI e do Departamento de Fundamentos da Educação, do Centro de Ciências da Educação, da Universidade Federal do Piauí. Presidente da Comissão de Governança dos Programas de Formação Inicial de Professores, da Universidade Federal do Piauí. Líder do Núcleo Interdisciplinar de Pesquisas em Educação e Epistemologia da Prática Profissional (NIPEEPP). E-mail: adalvac@uol.com.br.
}

${ }^{3}$ Este artigo possui sua versão original publicada na obra FRANÇA-CARVALHO, A. D. et al. (org.) Notas de aula: dialogando sobre práticas de aprendizagens na escola e na universidade. Teresina, EDUFPI, 2017. 
deficiência em uma sala de aula comum é garantida pela Constituição de 1988 (BRASIL, 1988).

Além deste documento, a Lei n. 9394, de 20 de dezembro de1996, mencionou que é dever do estado garantir a educação escolar pública, bem como atendimento especializado a estes educandos na rede regular de ensino (BRASIL, 1996). Tal perspectiva se estendeu ao Ensino Superior, e no âmbito da UFPI são disponibilizados recursos aos alunos com necessidades especiais. No caso dos deficientes auditivos, a instituição oferece interpretes durante as aulas, além de tradutores que auxiliam os alunos a leitura e compreensão dos textos em horários que contrapõe as aulas. Ressaltamos, que, esta foi nossa primeira experiência em lecionar para surdos, e que nenhuma das pesquisadoras envolvidas possuía domínio sobre a língua de sinais.

O objetivo geral do presente trabalho consiste em descrever experiências do ensino de Psicologia da Educação para alunos surdos no Ensino Superior. Bem como, conhecer métodos diferenciados para o ensino de Psicologia da Educação; descrever as relações estabelecidas entre o professor, os alunos e os interpretes; e, refletir sobre a sala de aula, enquanto, espaço educativo.

No intuito de corresponder a estes objetivos recorremos a pesquisa participativa, descritas por Richardson (1999) como uma metodologia cujas estratégias de intervenção baseada na construção de relações mais democráticas entre os atores, na qual o pesquisador envolve-se de maneira vertical, ou seja ele faz parte da pesquisa como ator. O lócus para a realização de tal trabalho, foi a sala de aula do curso de Letras/LIBRAS da UFPI, e os participantes foram a professora/pesquisadora em tirocínio, a professora/pesquisadora orientadora, oito alunos de graduação (4 surdos e 4 ouvintes) e três interpretes. Foi a interação entre eles que nos conduziu aos seguintes resultados.

\section{A DIDÁTICA E ORGANIZAÇÃO DAS AULAS}

A Didática não se restringe ao método de ensino, para Pimenta (2002) sua função é de dispor conhecimentos Pedagógicos aos professores, a exemplo disso, consideramos o planejamento, técnicas de ensino, habilidade na utilização de recursos, sistemática de avaliação, etc. A disciplina de Psicologia da Educação é uma disciplina obrigatória para todos os cursos de licenciatura, seus objetivos 
consistem em compreender as relações entre Psicologia e Educação, bem como, a importância da Psicologia na formação do educador; analisar os pressupostos teóricos que descrevem e explicam os processos de Desenvolvimento e Aprendizagem; e, refletir sobre as principais teorias do Desenvolvimento e da Aprendizagem segundo a base epistemológica, conceitos básicos e implicações pedagógicas.

A turma de 2015.1 do curso de Letras/LIBRAS a disciplina foi ministrada todas as sextas-feiras de 8 da manhã ao meio dia, durante o primeiro semestre de 2015, o que totalizou 60 horas. Os conteúdo dividiram-se em 3 Unidades, cuja as notas foram atribuídas com a base em somatórias de atividades, isso possibilitou analisar a compreensão dos alunos sob mais de uma perspectiva. O quadro abaixo descreve o tema das unidades, o conteúdo discutido em cada uma delas e os mecanismos de avaliação.

Quadro 1 - Descrição das Unidades da Disciplina de Psicologia da educação.

\begin{tabular}{|c|c|c|c|}
\hline UNIDADE & TEMA & CONTEÚDO & AVALIAÇĀO \\
\hline 1 & $\begin{array}{l}\text { A ciência } \\
\text { psicológica e a } \\
\text { Psicologia da } \\
\text { educação }\end{array}$ & $\begin{array}{l}\text { - Constituição histórica da } \\
\text { Psicologia e seu objeto de } \\
\text { estudo; Relações entre } \\
\text { psicologia e educação. }\end{array}$ & $\begin{array}{l}\text { Linha do Tempo; } \\
\text { Mapa conceitual; } \\
\text { Produção de texto } \\
\text { (experiência com a } \\
\text { argila) }\end{array}$ \\
\hline 2 & $\begin{array}{l}\text { Desenvolvimento e } \\
\text { aprendizagem }\end{array}$ & $\begin{array}{l}\text { - Desenvolvimento: concepções, } \\
\text { conceitos, princípios e aspectos; } \\
\text { Aprendizagem: abordagens, } \\
\text { conceitos e características. }\end{array}$ & $\begin{array}{l}\text { Seminário e prova } \\
\text { escrita. }\end{array}$ \\
\hline 3 & $\begin{array}{c}\text { Teorias do } \\
\text { Desenvolvimento e } \\
\text { da aprendizagem }\end{array}$ & $\begin{array}{l}\text {-Teorias de Freud, Skiner, } \\
\text { Ausubell, Piaget, Vygotsky e } \\
\text { Wallon }\end{array}$ & $\begin{array}{l}\text { Seminário (Mobile) e } \\
\text { Portifólio. }\end{array}$ \\
\hline
\end{tabular}

Fonte: Dados das autoras, 2015

Libâneo (1990), assevera que a Didática trata-se da teoria geral do ensino, a ela cabe converter os objetivos sociais, políticos e pedagógicos em objetivos de ensino. Para o autor, ela também é responsável pela seleção dos conteúdos e métodos em função desses objetivos, e ainda estabelecer os vínculos entre ensino e aprendizagem, tendo em vista o desenvolvimento das capacidades intelectuais dos alunos. Assim, os conteúdos foram divididos em unidades, quanto aos métodos, conforme proposto no Plano de disciplina, as unidades foram trabalhadas sob diversos procedimentos de ensino, dentre eles, aula expositiva dialogada, estudos 
individuais e em grupo; leitura fichamento e debates sobre os textos, exibição de filmes, trabalhos teóricos e teóricos práticos.

Ressaltamos a característica de flexibilidade que deve existir nos planejamentos. No início da disciplina foram adotados métodos que não foram bem aceitos pelos alunos surdos, por exemplo, leitura e discussão de texto sem um auxílio visual, método eficaz em outras propostas de ensino da mesma disciplina, porém apenas com alunos ouvintes. Os alunos surdos demonstram dificuldades em assimilar atividades abstratas como discussões de textos sem um aparato visual, isso não significa a falta de potencial, mas, uma ressalva que indicou a reformulação em nossa didática, onde percebemos que existem peculiaridades neste formato de ensino.

Todos, surdos ou não têm o potencial para desenvolver competências cognitivas. O grau do potencial depende de uma variedade de fatores, da sua faixa etária, de seus interesses, do ambiente em que estão inseridos, e das experiências com que se depara e a capacidade de compreendê-las. (FEINSTEIN, 2011, p.523)

Partindo do pressuposto de que as experiências que são propostas influenciaram no desenvolvimento de aprendizagens dos alunos, assim como, propõe Feinstein (2011), as atividades de cunho abstrato foram substituídas por atividades mais visuais, que não se limitariam a slides, e que trariam os alunos a compreensão dos conteúdos a partir de uma perspectiva prática e reflexiva, considerando a limitação trazida pela surdez.

Nossa primeira ação de replanejamento ocorreu com a criação do caderno da compreensão e sugestão. Isso significa um caderno que circulava diariamente entre todos os alunos. Eles deveriam escrever em todas as aulas suas impressões sobre a aula, queixas, sugestões elogios, questionamentos, qualquer apontamento que ajudássemos a identificar potencialidades e dificuldades dos alunos e das professoras, ou dos métodos de ensino.

Outro ponto que precisou ser reformulado foram as avaliações escritas no formato de resenhas ou sínteses, pois, os alunos surdos possuíam dificuldade de escrever em português e as professoras de compreender a leitura dos textos, mesmo com o auxílio dos interpretes, o que nos levou a uma perspectiva de outas avaliações, utilizando seminários e construção de diários, por exemplo. Foi a partir 
de diálogos e sugestões de todo o grupo que elaboramos e adequamos metodologias inovadoras para o trabalho dos conteúdos.

\section{METODOLOGIAS DIFERENCIADAS PARA O ENSINO DE PSICOLOGIA DA EDUCAÇÃO}

A escolha dos métodos e instrumentos de ensino também são elementos da Didática, estes deverão ser estabelecidos antes da aula. Conforme Heidt (2006), em sala de aula o docente está incumbido de duas funções, a incentivadora na qual o docente se aproveita da curiosidade dos discentes para despertar seu interesse e mobilizar esquemas cognitivos; e, orientadora, pois o docente também deve orientar o esforço do discente para aprender, ajudando a construir seu próprio conhecimento. As atividades selecionadas para o ensino de Psicologia da Educação para a turma de LIBRAS seguem esta perspectiva, de incentivar os alunos por meio da criatividade para alcançar a construção do conhecimento. A disciplina de Psicologia da Educação divide-se em 3 unidades, apresentaremos, a seguir, metodologias que destacaram-se no ensino da Psicologia da Educação para alunos surdos dentro de cada unidade.

\subsection{Identidade em argila}

A identidade configura-se como parte do objeto de estudo da Psicologia da educação, portanto, sua compreensão é importante para o desenvolvimento da disciplina. Antes da atividade com argila foi lido e discutido o texto "A construção social do sujeito" (SAVIS, 1994), para fundamentação da construção de conhecimentos prévios sobre identidade. No texto a autora discorre sobre as meninas lobos, Amala e Kamala, duas crianças indianas que na década de 1920 cresceram longe do convívio com outras pessoas e que não apresentavam um comportamento legitimamente humano. Savis (1994) ressalta que os homens transformam a natureza criando cultura, redefinindo cada vez mais, técnicas, instrumentos, conhecimentos, e transformam a si mesmos: desenvolvem suas funções mentais (percepção, atenção, memória, raciocínio) e a sua personalidade (sua maneira de sentir e atuar no mundo), na junção destes elementos se estabelece a identidade. 
Para Ciampa (2001) a construção da identidade associa-se a relação do individual com o plural, ou seja, no coletivo que habita cada pessoa. Para o autor, identidade é um metamorfosear-se a cada encontro, o que perpassa pela transformação pessoal do humano. Portanto, a identidade é de cada humano, aquilo que se define no agora, suas experiências anteriores e projeções. $\mathrm{Na}$ ideia de compreender este sentido de identidade, com a parceria dos alunos do curso de Artes, os discentes de Psicologia da educação foram apresentados as técnicas básicas da modelagem de argila. $O$ objetivo consistiu em que representássemos na argila elementos que reportassem a própria identidade (Figura 1).

Figura 1 - Trabalho com argila. Tema Identidade.

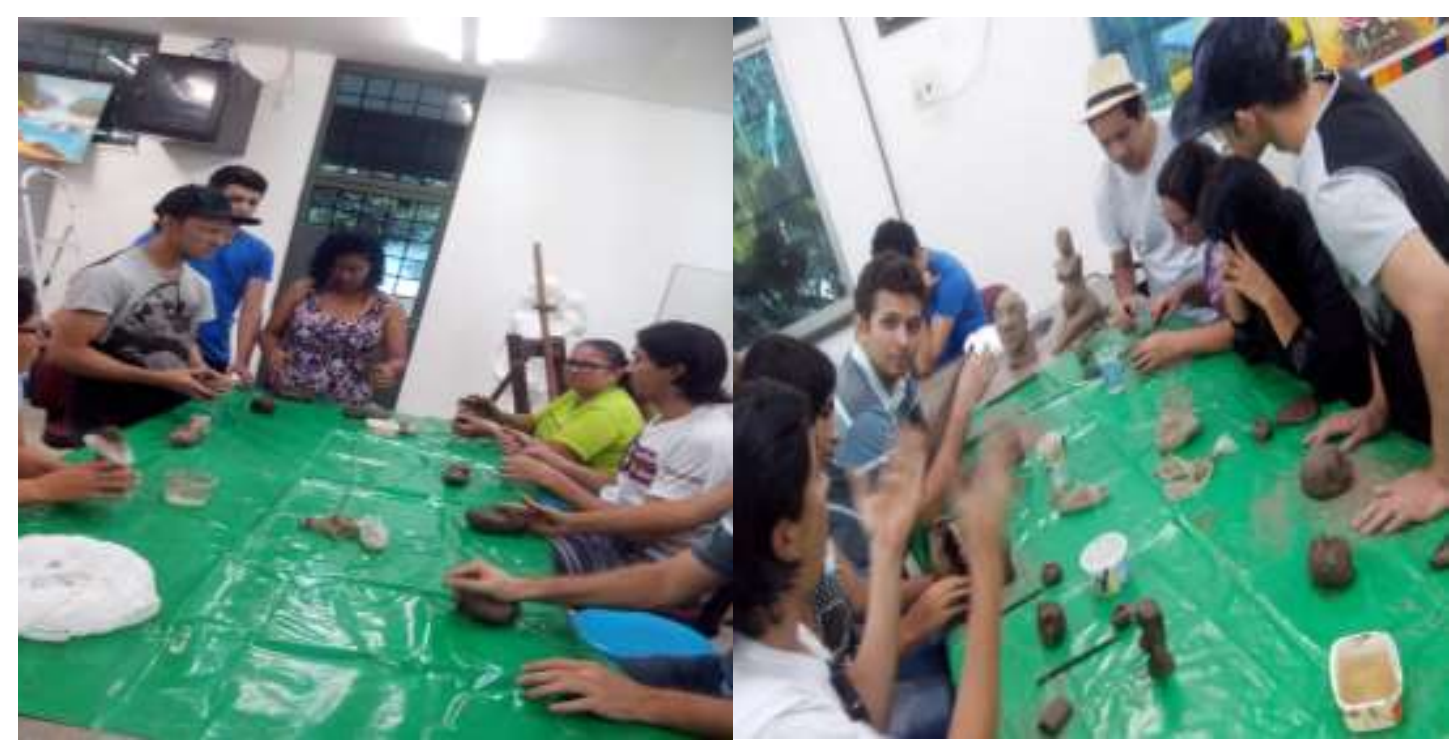

Fonte: Dados das autoras, 2015.

Desta maneira, os alunos modelaram na argila pequenos objetos que os representassem, após a construção da aula cada um descreveu de maneira satisfatória sua experiência, e compreensão sobre identidade, articulando a ideia do texto, a representação na argila e as discussões feitas em sala de aula e no ateliê.

\subsection{Teorias da aprendizagem no cabide}

O seminário é uma estratégia conhecida pelos estudantes universitários, mesmo que nem sempre seja considerada a melhor maneira de aprender 
determinado conteúdo, pois "Provavelmente porque nenhuma estratégia de ensino tenha sido tão mal utilizada pelos professores do ensino superior" (GIL, 2009, p. 172). O autor sugere que a estratégia possa ser desenvolvida individualmente ou em grupo, e que possibilitaria ao aluno aprender posicionamentos que levem em consideração a interpretação dele e dos demais integrantes da turma, além de do exercício da pesquisa e do estudo orientado de forma autônoma.

Considerando a peculiaridade dos alunos surdos na língua escrita, e a dificuldade que as professoras tinham de compreender tais escritos, o seminário foi uma estratégia que permitia a expressão dos surdos e ouvintes por meio da ação dos interpretes (Figuras 2 e 3). O Seminário serviu de estratégia para o estudo do conteúdo "Desenvolvimento da aprendizagem", na qual utilizamos a perspectiva mais tradicional com o auxílio do data show. Existem diversas maneiras de apresentar os seminários, formatos que se desprendam da exposição de slides, dito isso, a proposta de apresentar os seminários em mobiles com base de cabides para a exposição das teorias do Desenvolvimento e Aprendizagem.

Figura 2 - Alunos apresentando seminário no Cabide.

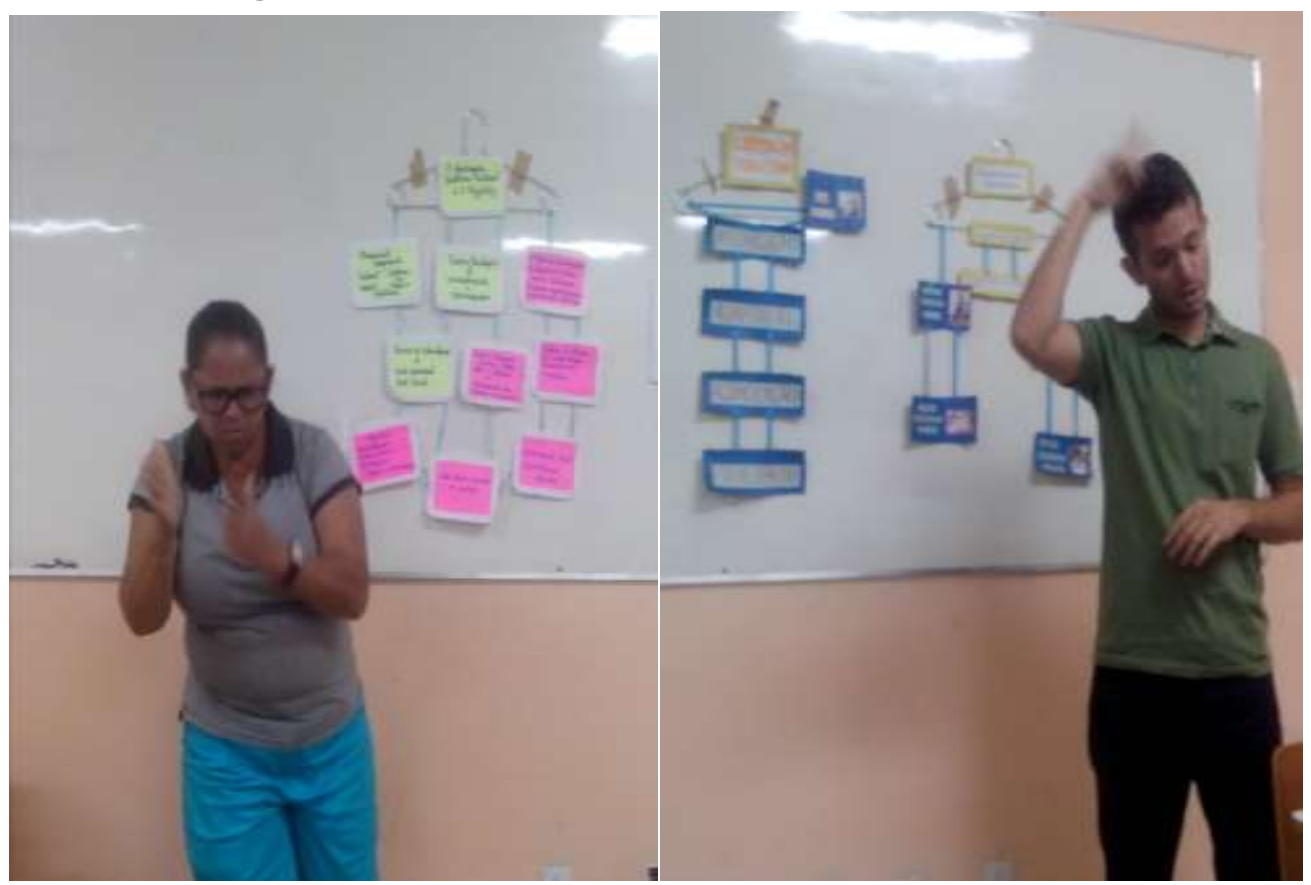

Fonte: Dados das autoras, 2015. 
Figura 3 - Alunos e interpretes no momento do Seminário no Cabide.

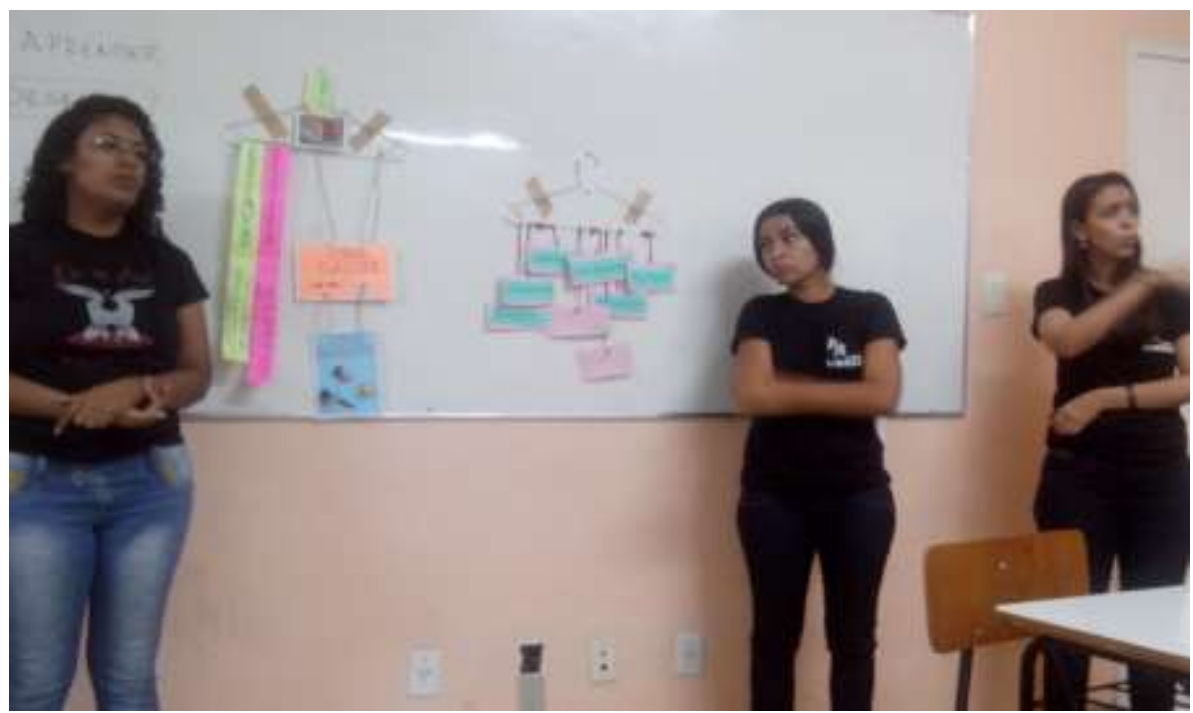

Fonte: Dados das autoras, 2015.

Os alunos foram divididos em duplas, as quais construíram um mapa conceitual que abordava as teorias da aprendizagem selecionadas com base no texto de Coutinho e Moreira (1993) previamente lidos que contemplaram as seguintes teorias: Inatista, Behaviorista, Piagetana, e Histórico cultural.

Os mapas conceituais, segundo Novak e Gowin (1986), são estruturas esquemáticas que delineiam o conjunto de ideias e conceitos chaves interligados em uma espécie de rede de proposições. O objetivo desta estratégia de ensino é apresentar mais claramente a exposição do conhecimento e organizá-lo segundo a compreensão do autor do mapa em representações gráficas, que indicam relações entre palavras e conceitos. No caso desta turma em específico, além das palavras chaves e conceitos permitimos que os alunos também usassem imagens. Os mapas conceituais foram construídos pelas duplas e serviram de aparato e organizador das falas na apresentação do seminário em móbile. Ressaltamos que durante a exposição dos móbiles a comunicação de surdo para ouvinte e ouvinte para surdo foi mediada pelos interpretes, assim como em todas as atividades.

\subsection{Portfólio com diário de atividades}

Ao fim da disciplina, os alunos, individualmente, organizaram um copilado de impressões sobre todas as atividades desenvolvidas no semestre, o portfólio. Tal material serviu como base para a terceira nota (Figura 4). Segundo Hernández (1998) portfólio consiste no agrupamento de diferentes classes de documentos 
(notas pessoais, experiências de aula, trabalhos pontuais, controle de aprendizagem, conexões com outros temas fora da sala de aula, representações visuais, etc.) que proporciona evidências do conhecimento que foi construído, das estratégias utilizadas e da compreensão dos temas de quem elaborou.

Figura 4 - Portfólios de atividades.

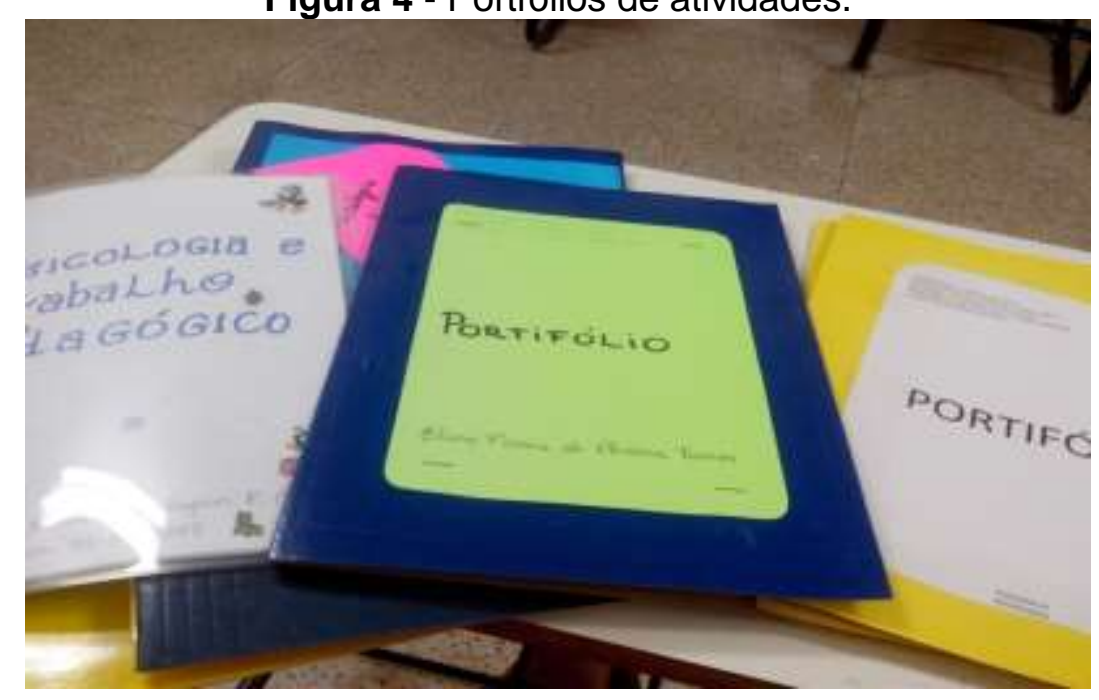

Fonte: Dados das autoras, 2015.

Foi disponibilizada ao longo do semestre uma caixa com materiais (como papel colorido, revistas, tesoura, cola, pastas colecionadoras, tinta, canetas coloridas, etc.) para a construção do portfólio de maneira mais lúdica, no intuito de construções mais visuais que produções de textos mais densas. No portfólio, alguns alunos descreveram a didática e características das professoras. Além disso, caracterizaram cada uma das unidades utilizando resumos e esquemas dos textos, corte e colagem, imagens de revistas e impressas, desenhos e fotografias.

As atividades aqui descritas são recortes da proposta didática da disciplina de Psicologia da Educação no curso de Letras/LIBRAS da UFPI. Além das três estratégias expostas, a disciplina foi ministrada com aulas expositivas dialogadas, construção de cartazes, estudos dirigidos, exposição de slides, exposição de vídeos legendados.

\section{EPÍLOGO}

A experiência do ensino de Psicologia da Educação para o curso de licenciatura em Letras/LIBRAS proporcionou novos desafios às professoras, 
exacerbando suas zonas de conforto, permitindo a inovação de prática docente. Para os alunos, a Psicologia da educação, ultrapassa o rotulo de mais uma disciplina pedagógica obrigatória, para impulsionadora de um pensamento reflexivo sobre o processo de desenvolvimento humano e aprendizagem.

O objetivo geral consistiu em descrever as experiências do ensino de Psicologia da educação para alunos surdos, se concretiza com a exposição de práticas que contribuíram para todos os envolvidos na disciplina. Conhecer essas metodologias diferenciadas para o ensino de Psicologia da educação, poderá subsidiar estudos sobre as didáticas relacionadas ao ensino de surdos em âmbito universitário, motivando ainda a criatividade de professores que se deparam com esses alunos sem estarem preparados.

Parafraseando Feinstein (2011), concluímos que é necessário dar-se aos surdos a oportunidade para que se envolvam em diálogos significativos e relevantes, é necessário criar situações que permitam que o surdo (ou ouvinte) seja o verdadeiro participante de conversas. $\mathrm{O}$ intuito disso é dar a eles oportunidades de serem criativos, de regatearem e de fazerem inferências. Tais práticas contribuem para se tornarem indivíduos mais assertivos, reflexivos e, sobretudo, independentes.

\section{REFERÊNCIAS}

BRASIL. Lei n. 9.394, de 20 de dezembro de 1996. Estabelece a Lei de Diretrizes e Bases da Educação Nacional. Disponível em: < http://www.planalto.gov.br/ccivil_03/leis/19394 .htm>. Acesso em: 30 maio. 2017.

. Constituição da República Federativa do Brasil, 1988. Organização de

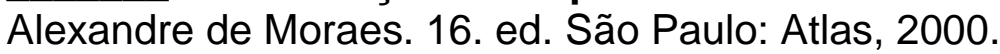

. Ministério da Educação. Secretaria de Educação Especial. Lei n. 10.436, de 24 de abril de 2002. Dispõe sobre a Língua Brasileira de Sinais - LIBRAS e dá outras providências. Disponível em: < http://www.planalto.gov.br/ccivil_03/leis/2002//10436.htm>. Acesso em: 30 maio. 2017.

CIAMPA, A. da C. A estória do Severino e a História da Severina: um ensaio de Psicologia Social. São Paulo: Brasiliense, 2001.

COUTINHO, M.T.; MOREIRA, M. Psicologia da Educação. Belo Horizonte: Lê, 1993. 
DOURADO, A. C. S.; FRANÇÃ-CARVALHO, A. D. Aulas de psicologia da educação: o fazer pedagógico com alunos surdos. In: FRANÇA-CARVALHO, A. D. et al. (org.). Notas de aula: dialogando sobre práticas de aprendizagens na escola e na universidade. Teresina, EDUFPI, 2017. p.113-125.

FEINSTEIN, S. A aprendizagem e o cérebro. Lisboa, Portugal: Instituto Piaget/ Horizontes Pedagógicos, 2011.

GLAT, R.; NOGUEIRA, M. L. de L. Políticas educacionais e a formação de professores para a educação inclusiva no Brasil. Revista Integração, v. 24, ano 14; Brasília: MEC/SEESP, p.22-27, 2002.

GIL, A. C. Como elaborar projetos de pesquisa. 4ed. São Paulo: Atlas, 2009.

HAIDT, R. C.C. Curso de Didática Geral. 8. ed. São Paulo: Ática, 2006.

HERNÁNDEZ, F. Transgressão e Mudança na e Educação: os projetos de trabalho. Porto Alegre : Artmed 1998.

LIBÂNEO, J. C. Didática. São Paulo: Cortez, 1990.

NOVAK, J. D. \& GOWIN, D. B. Aprender a Aprender. Lisboa: Plátano Edições Técnicas, 1986.

PIMENTA, S. G. Professor reflexivo: construindo uma crítica. In: PIMENTA, S. G.; GHERDIN, E. Professor reflexivo no Brasil: gênese e crítica de um conceito. 2. ed. São Paulo: Cortez, 2002, p. 12-52.

RICHARDSON, R. J. et al. Pesquisa social: métodos e técnicas. 3. ed. São Paulo: Atlas, 1999.

SAVIS, C. Psicologia na educação. São Paulo:Cortez,1994. 